\title{
Sympathotomy for severe compensatory hyperhidrosis in the trunk due to traumatic cervical spinal cord injury
}

\author{
Jung Wook Han, Jae Jun Kim, Seong Cheol Jeong, Yong Hwan Kim, In Sub Kim \\ Department of Thoracic and Cardiovascular Surgery, Uijeongbu St. Mary's Hospital, College of Medicine, The Catholic University of Korea, Seoul, \\ Republic of Korea \\ Correspondence to: Jae Jun Kim, MD, PhD. Department of Thoracic and Cardiovascular Surgery, Uijeongbu St. Mary's Hospital, College of Medicine, \\ The Catholic University of Korea, 271 Cheonbo Ro, Uijeongbu-si, Gyeonggi-do, 11765 Seoul, Republic of Korea. Email: medkjj@hanmail.net.
}

Submitted Dec 02, 2019. Accepted for publication Jan 16, 2020.

doi: $10.21037 /$ jtd.2020.01.62

View this article at: http://dx.doi.org/10.21037/jtd.2020.01.62

\section{Introduction}

Primary hyperhidrosis is a condition characterized by excessive and uncontrollable sweating $(1,2)$. Surgical sympathetic blockades such as sympathotomy or sympathicotomy have been accepted as the most effective treatment option for severe hyperhidrosis when medical treatment fails $(3,4)$. However, postoperative compensatory hyperhidrosis is a challenging complication that can cause patients to regret undergoing surgery and lead to a surgeon's reluctance to choose surgery as the first treatment option for primary hyperhidrosis, especially craniofacial hyperhidrosis $(1,3)$. Compensatory hyperhidrosis most commonly affects the trunk after sympathetic blockades $(5,6)$. Herein, we present a rare case of a successful sympathotomy for severe compensatory hyperhidrosis in the trunk caused by traumatic cervical spinal cord injury.

\section{Case presentations}

A 32-year-old man was admitted to our clinic after presenting with severe sweating in the trunk. He had a history of primary hyperhidrosis in the face and hands since adolescence. Two years ago, he underwent an anterior cervical spinal fusion due to traumatic cervical spinal injury (incomplete spinal cord injury with central cord syndrome and traumatic herniation of the nucleus pulposus in C5-6) after a car accident. There was no traumatic injury in the thorax. Although his facial hyperhidrosis disappeared after trauma and surgery, the patient experienced severe sweating in the trunk and hands, and he needed to change cloths several times a day. Conservative treatment failed, so we selected a surgical approach for treatment of the patient's truncal and palmar hyperhidrosis. With the patient under single lumen endotracheal general anesthesia in the prone position, we performed 5-mm, two-port thoracoscopic, R3 sympathicotomy for palmar hyperhidrosis, using a $\mathrm{CO}_{2}$ gas insufflation via the sixth intercostal space on the post-axillary line and the seventh intercostal space on the mid-scapular line. In addition, we performed sympathetic ganglion ablation from T5 to T8 for trunk hyperhidrosis. The patient's postoperative course was uneventful, and he was discharged without any complications on the first postoperative day. The patient's palmar had completely resolved and truncal hyperhidrosis had much improved. Infrared thermography showed elevations in temperature primarily of the trunk and hands, indicating palmar and truncal hyperhidrosis were improved after surgery (Figure 1). Six months after surgery, the patient was very satisfied with the surgical outcome, although mild compensatory hyperhidrosis had developed in the thighs and buttocks.

\section{Discussions}

This report described a rare case of excessive trunk hyperhidrosis that was considered as compensatory hyperhidrosis secondary to traumatic cervical spinal cord injury. The patient had a previous history of severe facial and palmar hyperhidrosis. Although his facial hyperhidrosis resolved after cervical spine trauma and cervical spinal fusion surgery, the patient's palmar hyperhidrosis persisted and he developed severe trunk hyperhidrosis. Because sympathetic blockade of the sympathetic nerves related to facial 

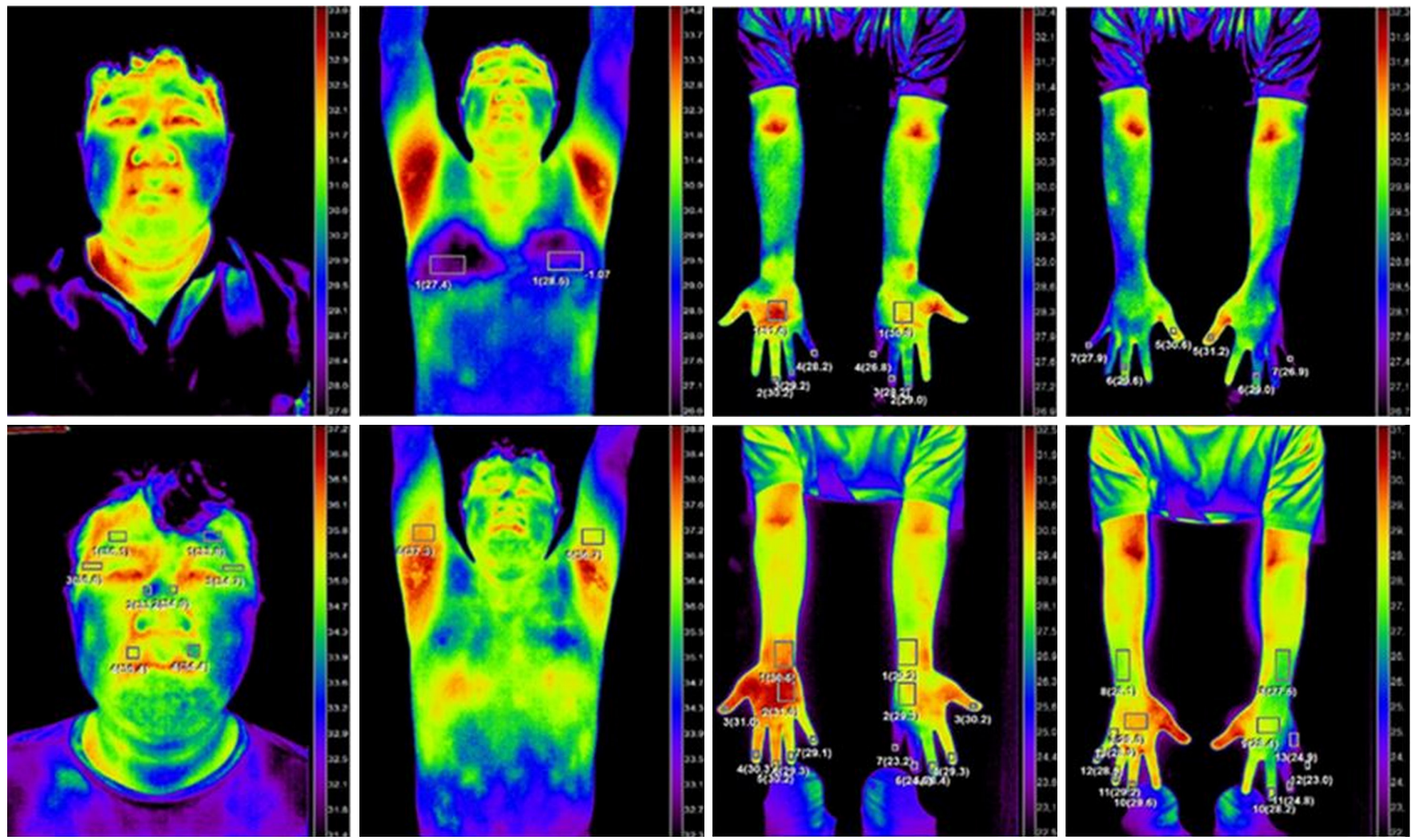

Figure 1 Infrared thermographic images were obtained preoperatively (top) and on the seventh postoperative day (bottom).

hyperhidrosis resolves facial hyperhidrosis and usually causes compensatory hyperhidrosis, we assumed that the patient's cervical injury, acting as a sympathetic blockade, resolved his facial hyperhidrosis and caused compensatory hyperhidrosis in the trunk. Interestingly, palmar hyperhidrosis is usually improved after sympathicotomy for facial hyperhidrosis, but palmar hyperhidrosis persisted in this case $(1,4)$. We hypothesized that the palmar hyperhidrosis persisted because the sympathetic nerves related to palmar hyperhidrosis were intact and without injury. Hyperhidrosis has been reported to be caused by various conditions, including cervical spinal trauma and tumors $(2,7)$. However, to the best of our knowledge, the present case represents the first report of facial hyperhidrosis resolved by cervical spinal trauma along with compensatory hyperhidrosis in the trunk. Although we do not know whether the excessive sweating in the trunk was compensatory hyperhidrosis caused by the sympathetic nerve injury, we favored compensatory hyperhidrosis because facial hyperhidrosis was resolved and sympathetic blockade for facial hyperhidrosis usually develops compensatory hyperhidrosis. The severe hyperhidrosis in the trunk and hands interfered with the patient's everyday activities, and medical treatment failed, leading to the selection of surgical sympathetic blockade for treatment. Trunk is innervated by ipsilateral sympathetic efferent fibers from segments T4 to T12 (2) and previous studies have reported successful management in the trunk with sympathetic blockade (T4-T7) via ablation or botulinum toxin $(1,3,6,8)$. We think that the ranges of sympathotomy for truncal compensatory hyperhidrosis are not defined yet. We did not perform T4 sympathotomy to prevent complications such as severe dry hands because we performed R3 sympathicotomy for palmar hyperhidrosis. If we did not perform R3 sympathicotomy, we included T4 sympathotomy. Therefore, we performed R3 sympathicotomy for palmar hyperhidrosis and added sympathetic ganglion ablation form T5 to T8 for trunk hyperhidrosis with electrocautery. The operative outcomes were satisfactory without any noticeable complications. As usual, postoperative mild compensatory hyperhidrosis in the thighs and buttocks was considered to be caused by R3 sympathicotomy for palmar hyperhidrosis. In conclusion, this case report described the resolution of facial hyperhidrosis and development of truncal compensatory hyperhidrosis after cervical spinal trauma. In addition, thoracoscopic 
sympathetic blockade of T5-T8 with electrocautery ablation seems effective, feasible, and without complications for severe compensatory hyperhidrosis in the trunk.

The authors are accountable for all aspects of the work in ensuring that questions related to the accuracy or integrity of any part of the work are appropriately investigated and resolved.

\section{Acknowledgments}

Funding: None.

\section{Footnote}

Conflicts of Interest: The authors have no conflict of interest to declare.

Ethical Statement: The authors are accountable for all aspects of the work in ensuring that questions related to the accuracy or integrity of any part of the work are appropriately investigated and resolved. Written informed consent was obtained from the patient for publication of this manuscript and any accompanying images.

Open Access Statement: This is an Open Access article distributed in accordance with the Creative Commons Attribution-NonCommercial-NoDerivs 4.0 International License (CC BY-NC-ND 4.0), which permits the noncommercial replication and distribution of the article with the strict proviso that no changes or edits are made and the original work is properly cited (including links to both the formal publication through the relevant DOI and the license).

Cite this article as: Han JW, Kim JJ, Jeong SC, Kim YH, Kim IS. Sympathotomy for severe compensatory hyperhidrosis in the trunk due to traumatic cervical spinal cord injury. J Thorac Dis 2020;12(3):1115-1117. doi: 10.21037/jtd.2020.01.62
See: https://creativecommons.org/licenses/by-nc-nd/4.0/.

\section{References}

1. Gunn TM, Davis DM, Speicher JE, et al. Expanded level of sympathetic chain removal does not increase the incidence or severity of compensatory hyperhidrosis after endoscopic thoracic sympathectomy. J Thorac Cardiovasc Surg 2014;148:2673-6.

2. Schick CH. Pathophysiology of Hyperhidrosis. Thorac Surg Clin 2016;26:389-93.

3. Karlsson-Groth A, Rystedt A, Swartling C. Treatment of compensatory hyperhidrosis after sympathectomy with botulinum toxin and anticholinergics. Clin Auton Res 2015;25:161-7.

4. Vannucci F, Araújo JA. Thoracic sympathectomy for hyperhidrosis: from surgical indications to clinical results. J Thorac Dis 2017;9:S178-92.

5. Kim WO, Kil HK, Yoon KB, et al. Botulinum toxin: a treatment for compensatory hyperhidrosis in the trunk. Dermatol Surg 2009;35:833-8; discussion 838.

6. Deniz S, Kavaklı K, Çaylak H, et al. Treatment of compensatory hyperhidrosis of the trunk with radiofrequency ablation. Agri 2015;27:42-6.

7. Shi W, Zhao B, Yao J, et al. Intramedullary Spinal Cord Ganglioglioma Presenting as Hyperhidrosis: A Rare Case Report and Literature Review. World Neurosurg 2019;127:232-6.

8. Moon DH, Kang DY, Kim DW, et al. Early results of new endoscopic thoracic sympathectomy for craniofacial hyperhidrosis. J Thorac Dis 2018;10:3627-31. 